Letter to Editor

\title{
A study on prevalence and pattern of clinically recognisable congenital malformations in babies born in a rural medical college hospital in West Bengal, India
}

\author{
Dey S. ${ }^{1}$, Pal A.C. ${ }^{2}$, Nandi MK. ${ }^{3}$, Agarwalla P. ${ }^{4}$ \\ ${ }^{1}$ Dr. Subhendu Dey, Assistant Professor, Department of Pediatric Medicine, BS Medical College, Bankura, ${ }^{2}$ Dr. Abhay \\ Charan Pal, Associate Professor, Department of Pediatric Medicine; BS Medical College, Bankura, West Bengal, \\ ${ }^{3}$ Dr. Malay Kumar Nandi, Assistant Professor, Department of G \& O, BS Medical College, Bankura, ${ }^{4}$ Dr. Prasant \\ Agarwalla, $2^{\text {nd }}$ yr PGT, Dept. of Pediatric Medicine, BS Medical College, Bankura, West Bengal, India.
}

Corresponding Author: Dr. Abhay Charan Pal, Subhankar Sarani, PO \& Dist. Bankura, West Bengal, India, E-mail: abhaypa180@gmail.com

\begin{abstract}
Introduction: Congenital anomalies are a major cause of neonatal mortality and morbidity both in developed and developing countries. It accounts for $8-15 \%$ of perinatal deaths and $13-16 \%$ of neonatal deaths in India. Aims and Objective: This study was done to determine the proportion and changing pattern of congenital anomalies in live newborns and to study the associated maternal and perinatal risk factors. Materials and Method: This is a hospital based cross-sectional descriptive study and was conducted in Bankura Sammalini Medical College and Hospital, West Bengal India during the period July 2016 to December 2017. Results: During his period 31989 babies were born, of which 598 had congenital malformations, making the prevalence $1.86 \%$. Distribution of malformation was predominant among males than in females (66.7 vs. $32.6 \%$; p < 0.05). Discussion: The predominant system involved was musculo-skeletal system followed by cardiovascular and genitourinary system. Congenital anomalies were more likely associated with low birth weight, prematurity, multiparity, consanguinity and caesarean delivery. Various maternal risk factors were studied as well as the role of early preventive interventionalstrategies. Conclusion: Public awareness is to be created and early prenatal diagnosis and management of common anomalies is highly recommended.
\end{abstract}

Key words: Congenital anomaly, Cross-sectional study, India, Prevalence, Risk factors

\section{Introduction}

Congenital anomalies or birth defects are among the leading causes of infant mortality and morbidity around the world. The impact of congenital anomalies is particularly severe in middle- and low-income countries where health care resources are limited. The prevalence of congenital anomalies varies in different parts of the world, which could reflect different aetiological factors in different geographical regions.

It accounts for $8-15 \%$ perinatal deaths and $13-16 \%$ neonatal death in India. It is not only a leading cause of fetal loss but also contributes significantly to preterm birth, childhood and adult morbidity. According to World Health organisation (WHO) fact sheet of October 2012, congenital anomalies can be defined as structural or functional anomalies which are present at the time of

Manuscript received: $8^{\text {th }}$ November 2018

Reviewed: $18^{\text {th }}$ November 2018

Author Corrected: $24^{\text {th }}$ November 2018

Accepted for Publication: $27^{\text {th }}$ November 2018 birth [1]. Structural defects of prenatal origin are classified into the following three groups, according to the cause, timing and extent of the developmental disturbance: Malformations (defective organogenesis), Dysplasia (abnormal cell or tissue structure), Deformation (mechanicallyinduced changes of normal structure) [2]. About $20 \%$ of all major congenital malformation is genetically transmitted by a monogenetic abnormality, $5-10 \%$ is due to chromosomal anomalies, and $2-10 \%$ is due to viral infection. In about $60 \%$ the cause is unknown and appears to multifactorial [3].

Exogenous etiological factors include teratogenic medicines like vit-A derivatives and maternal metabolic disease such as diabetes mellitus. Toxic effects on the human embryo have been demonstrated for the following substances alcohol, androgen, carbamazepine, coumarin derivativesetc. 
Letter to Editor

By International convention frequency of congenital malformation is reported as prevalence rather than incidence, as congenital malformations are not newly arising disease in the usual sense; but rather disorders affecting a given population at a given moment of time (the time of birth). Prevalence of major malformation has been variously reported as $3-4 \%$ to $6-8 \%[4,5]$. Congenital abnormalities play a major role in a morbidity and mortality of neonates and children [6].

Due to high cost of treatment and rehabilitation of these anomalies, early identification of causative and risk factors and early prevention is necessary where possible. In the tropical countries malnutrition and infection are main causes of infant morbidity and mortality while in temperate zones cancer, accidents and congenital abnormalities are the key causes of infant morbidity and mortality. Prevalence studies of congenital malformation are useful to establish baseline rates, to document changes over time and to identify clues to etiologic. They are also important for health service planning and evaluating antenatal screening in population with high risk. Such studies are important as those help to raise the awareness of surgical intervention and to emphasize the loss of babies with congenital malformation [7]. The present study was conducted with an intention to determine the prevalence of congenital malformation

\section{Aims and Objectives}

In developing countries like India the leading cause of neonatal mortality is sepsis and low birth weight with its complications; in the coming years owing to improved perinatal and neonatal care, mortality due to sepsis and low birth weight will be reduced significantly and congenital malformation may become a leading cause of neonatal mortality. The current study was carried with the objective to determine the overall prevalence and pattern ofclinically recognisable congenital malformation in live birth and the associated maternal and perinatal risk factors.

\section{Material and Methods}

Place and design of Study: This cross-sectional descriptive study was carried out in the Sick newborn Care Unit. (SNCU) of a rural Medical College Hospital in Bankura, West Bengal during the period of July 2016 to December 2017.

\section{Results}

During the study period, 32325 new borns were born in our institution out of which 31989 (97.7\%) were live births and $765(2.3 \%)$ were stillborn. The number of babies with congenital malformations diagnosed at birth was 598 had congenital malformations, making the prevalence 1.86\%. Among all the newborns, 182 babies were born of twin 


\section{Letter to Editor}

delivery, 13 of triplet delivery 8 out of 195 babies that were products of multiple gestations, had one or more congenital anomalies. Distribution of malformation was predominant among males than in females $(66.7$ vs. $32.6 \%$; $<0.05)$. The congenital anomalies affected significantly higher proportion of male babies $399(2.11 \%)$ than their female counterparts $195(1.48 \%)$.

Table -1: Shows frequency and sex distributions of congenital Anomaly

\begin{tabular}{|c|c|c|c|}
\hline Variables & Number & No of Babies with Anomaly & Percentage \\
\hline Live Birth & 31989 & 598 & 1.86 \\
\hline Male & 18873 & 399 & 2.11 \\
\hline Female & 13100 & 195 & 1.48 \\
\hline Ambiguos & 16 & 1 & 6.25 \\
\hline
\end{tabular}

Table-2 A: System wise Distribution of Congenital Anomalies

\begin{tabular}{|c|c|c|}
\hline System & Number & Percentage \\
\hline Musculoskeletal & 229 & 38.29 \\
\hline - Cleft Lip & 40 & 6.68 \\
\hline - Cleft Palate & 21 & 3.51 \\
\hline - CTEV & 126 & 21.07 \\
\hline - Polydactaly/Syndactaly & 33 & 5.51 \\
\hline - Osteogenesis Imperfacta & 4 & 0.66 \\
\hline - Vertebral Anomaly & 3 & 0.50 \\
\hline - Phocomelia & 2 & 0.33 \\
\hline Cardiovascular system & 65 & 10.86 \\
\hline - Acyanotic CHD & 39 & 6.52 \\
\hline - Cyanotic CHD & 19 & 3.17 \\
\hline - Complex CHD & 7 & 1.17 \\
\hline Gastrointestinal system & 35 & 5.85 \\
\hline - Duodenal atresia & 6 & 1.00 \\
\hline - Omphalocele & 7 & 1.10 \\
\hline - Extrophy of bladder & 3 & 0.50 \\
\hline - Exomphalos & 3 & 0.50 \\
\hline - Anorectal malformations & 13 & 2.17 \\
\hline - Gastroschisis & 1 & 0.16 \\
\hline - Oesophageal Atresia & 2 & 0.33 \\
\hline Central nervous system & 38 & 6.35 \\
\hline - Microcephaly & 7 & 1.17 \\
\hline - Hydrocephalus & 12 & 2.00 \\
\hline - Meningoencephalocele & 3 & 0.50 \\
\hline - Meningomyelocele & 5 & 0.83 \\
\hline - Spina bifida & 1 & 0.16 \\
\hline - Encephalocele & 2 & 0.33 \\
\hline - Meningocele & 3 & 0.50 \\
\hline - Anencephaly & 5 & 0.83 \\
\hline Urogenital system & 63 & 10.53 \\
\hline - Hypospadias & 13 & 2.17 \\
\hline - Micropenis & 1 & 0.16 \\
\hline - Ambiguous genitalia & 16 & 2.67 \\
\hline - Congenital hydrocele & 10 & 1.67 \\
\hline - Undescendedtestis & 4 & 0.66 \\
\hline - Polycystic Kidney & 3 & 0.50 \\
\hline - Hydroureter & 3 & 0.50 \\
\hline - Hydronephrosis & 10 & 1.67 \\
\hline - Posterior urethral valve & 3 & 0.50 \\
\hline Respiratory system & 14 & 2.34 \\
\hline - Laryngomalacia & 8 & 1.33 \\
\hline - Choanal atresia & 1 & 0.1 \\
\hline - Diaphragmatic hernia & 3 & 0.50 \\
\hline - Eventration of Diaphragm & 2 & 0.33 \\
\hline
\end{tabular}




\section{Letter to Editor}

Table 2 B : System wise Distribution of Congenital Anomalies

\begin{tabular}{|l|c|c|}
\hline Skin & $\mathbf{5 0}$ & $\mathbf{8 . 3 6}$ \\
\hline$\bullet$ Preauricular Tag/Skin tags & 16 & 2.67 \\
\hline$\bullet$ Hemangioma & 21 & 3.51 \\
\hline$\bullet$ Aplasia Cutis & 2 & 0.33 \\
\hline$\bullet$ Piebaldism & 2 & 0.33 \\
\hline$\bullet$ Giant hairy nevus & 1 & 0.33 \\
\hline$\bullet$ Blueberry Muffin & 3 & 0.16 \\
\hline$\bullet$ Others & $\mathbf{9}$ & 0.50 \\
\hline Eye & 3 & $\mathbf{1 . 5 0}$ \\
\hline$\bullet$ Microphthalmia & 4 & 0.50 \\
\hline$\bullet$ Anophthalmia & 2 & 0.66 \\
\hline$\bullet$ Congenital Ptosis & $\mathbf{3 1}$ & 0.33 \\
\hline Syndromes & 1 & $\mathbf{5 . 1 8}$ \\
\hline$\bullet$ Holt-Oram syndrome & 7 & 0.16 \\
\hline$\bullet$ Pierre Robin Syndrome & 2 & 1.17 \\
\hline$\bullet$ Prune Belly Syndrome & 20 & 0.33 \\
\hline$\bullet$ Down syndrome & 1 & 3.34 \\
\hline$\bullet$ TAR Syndrome & & 0.16 \\
\hline
\end{tabular}

Table-3: Association between Congenital Malformations and Maternal and Perinatal Risk Factors

\begin{tabular}{|c|c|c|c|c|}
\hline \multirow[t]{2}{*}{ Variable } & \multirow[t]{2}{*}{ Groups } & \multirow[t]{2}{*}{ Total No } & \multicolumn{2}{|c|}{ Congenital Anomaly } \\
\hline & & & No & $\%$ \\
\hline \multirow[t]{4}{*}{ Birth Weight } & $<1000 \mathrm{gr}$ & 221 & 8 & 3.6 \\
\hline & $1000-1499 \mathrm{gr}$ & 1055 & 32 & 3 \\
\hline & $1500-2499 \mathrm{gr}$ & 10422 & 214 & 2 \\
\hline & $>2500 \mathrm{gr}$ & 20291 & 344 & 1.6 \\
\hline \multirow[t]{3}{*}{ Gestation } & Preterm & 11698 & 252 & 2.16 \\
\hline & Term & 19204 & 328 & 1.7 \\
\hline & Post Term & 1087 & 18 & 1.6 \\
\hline \multirow[t]{3}{*}{ Maternal Age } & $<20$ years & 2559 & 19 & 0.74 \\
\hline & 20- 30 years & 27350 & 323 & 1.18 \\
\hline & $>30$ years & 2080 & 256 & 12.3 \\
\hline \multirow[t]{2}{*}{ Parity } & Primi & 11836 & 272 & 2.29 \\
\hline & Multi & 20153 & 327 & 1.62 \\
\hline \multirow[t]{3}{*}{ No of Fetus } & Single & 31694 & 591 & 1.86 \\
\hline & Twin & 182 & 8 & 4.39 \\
\hline & Triplet & 13 & 1 & \\
\hline \multirow[t]{3}{*}{ Mode of Delivery } & Vaginal & 22040 & 388 & 1.76 \\
\hline & AVD & 186 & 3 & 1.61 \\
\hline & $\mathrm{CS}$ & 9763 & 207 & 2.12 \\
\hline Consanguinity & Present & 35 & 3 & 8.5 \\
\hline
\end{tabular}

Mother less than 20 years has $1.95 \%$ babies with congenital anomalies whereas mothers between 20 and 30 years have maximum number of babies with congenital anomalies (87.2\%). There was a history of oligohydramnios in 33 (5.5\%) cases and polyhydramnios in $19(3.1 \%$ ) cases. There was $13.2 \%$ mother with babies with congenital anomaly who had history of previous abortions; $19 \%$ where diabetic mothers Prematurity and LBW was found to have a higher risk of congenital anomalies. The occurrence was about 2 times more in case of preterm delivery as compared with the term ones, making it statistically significant. Mode of delivery was also associated with congenital anomaly and it was more in case of caesarean deliveries. 
Letter to Editor

\section{Discussion}

The pattern and prevalence of congenital anomalies may vary over time or with geographical location, reflecting a complex interaction of known and unknown genetic and environmental factors including sociocultural, racial and ethnic variables [8] with improved control of infections and nutritional deficiency diseases, congenital malformations have become important causes of perinatal mortality in developing countries like India [9].

In the present study, the prevalence of congenital malformations in the newborns were $1.86 \%$, which is comparable with the earlier studies from India, which reported incidence of $2.72 \%$ and $1.9 \%$ [10]. There are other reports from different parts of the world representing different frequency of congenital malformations. [11, 12]. Although we got nearly the same result as reported in other studies, [13]. The number of documented birth defects in infant is increasing antenatally and during neonatal period due to advanced diagnostic technology, especially USG and echocardiography. The prevalence of congenital anomaly would have been more than the present rate, if we could have included the abortions and stillbirths.

With regard to pattern of congenital anomalies in the study, the most common system involved was musculoskeletal system (38.2\%), followed by cardiovascular system $(10.86 \%)$, genitourinary $(10.5 \%)$, gastro-intestinal tract (GIT) (5.81\%), CNS (6.37\%), skin $(7.85 \%)$ etc., This was comparable with studies conducted by others $(16,17)$ Some studies however recorded higher incidence of CNS malformations followed by GIT and musculoskeletal system, [14] whereas Suguna Bai et al[15] reported GI malformations as the most common one. More male babies with congenital anomalies than females were noted in the present study. Male preponderance was like the other studies $[9,10]$.

Association of low birth weight with increased risk of congenital malformation was noted in this study which is in line with previous studies $[18,19,20]$. The prevalence of congenital malformations was higher in preterm babies as compared to full term neonates [21].

Earlier data showed a definite increase in prevalence of congenital malformation in babies born to consanguineous marriage [21]. 35 cases had a history of consanguinity in our study. This study has statistically shown that mothers, above 30 years of age are at a higher risk of producing malformed babies. Sagunabai et al $[22,23]$ reported that mothers' age more than 35 years have a greater risk of giving birth to malformed babies whereas Datta et al [14] documented statistically insignificant association of increased maternal age and congenital malformation.

Congenital talipes equinovarus (CTEV) was the commonest musculoskeletal abnormalities observed in our study. Among the genitourinary tract anomalies, undescended testis hypospadias, and polycystic kidney were the most prevalent lesions. In the central nervous system, the most common anomaly found was Hydrocephalus followed by Microcephaly, meningomyelocele and meningocele.

The present study helps us to know the pattern of congenital malformations prevalent in this part of rural West Bengal. Observations made in this study also help us to know the possible correlation of various factors as to the cause of congenital anomalies.

Most of the observations are comparable with the similar studies undertaken in other parts of the country.

However some of the observations differ which is expected given the nature of various studies like hospital versuscommunity based, differences ingeographical and environmental factors, differences in time period for follow up, criteriafor classification used etc.

Despite the high risk of recurrence of congenital malformations, there are no well-accepted preventive measures in developing countries like India. It indicates that strong preventive measures for congenital anomalies in this region are needed. Increasing awareness about maternal care during pregnancy, educational programs on congenital malformations and the consequences of consanguineous marriages need to be highlighted to decrease the incidence of congenital anomalies and their co morbidities

Limitations- As it is a tertiary care hospital, prevalence calculated may be higher than the general population in this hospital-based study. Hence, the data cannot be projected to the general population, for which population-based studies are necessary. Secondly, we could not include the abortions and stillborns, because often the abnormalities are not obvious or visible externally. In those cases, a pathological autopsy is warranted and in most of the cases, parental consent is not available for pathological autopsy. 
Letter to Editor

\section{Conclusion}

This study has shown the prevalence and pattern of congenital malformations in this part of the country in association with various maternal risk factors. And it will definitely plan future strategies for prevention, prenatal diagnosis and early intervention and timely management when needed.

Authors Contributions: Dey S conceived the idea and actually conducted the study. He collected the data and finally drafted the manuscript. Pal AC revised the manuscript and added some intellectual contents to it. He provided necessary guidance whenever needed. Agarwal $\mathrm{P}$ helped in every step of the study and maintained co-ordination with other departments whenever necessary. Nandi M K. helped in collecting the labour room data as well as contributed in the statistical analysis and also added some intellectual contents. This study shows that prevalence of cardiac malfor-mations has reduced in comparison to earlier studies made in this same institution. However more intensive study is needed to comment regarding a changing trend of malformations.

Acknowledgment- All the parents of the babies included in the study. We thank the administration of Bankura Sammalini Medical College and Hospital (BSMCH) for their kind assistance in permitting us to use patient's data in this study. The contents of this study are solely responsibility of the authors and are in no way representative of the official views $\mathrm{BSMCH}$

Funding: Nil, Conflict of interest: None initiated, Perission from IRB: Yes

\section{References}

1. World Health Organization. Section on congenital anomalies. [Cited on 2012 Oct]. Available from: http:// www.who.int/mediacentre/factsheets/fs370/en/

2. Spranger J, Benirschke K, Hall JG, et al. Errors of morphogenesis: concepts and terms. Recommendations of an international working group. J Pediatr. 1982 Jan;100(1):160-5.

3. Pal Abhay charan et al-ISSN: 2279-0853, p-ISSN: 2279-0861. Volume 14, Issue 12 Ver. II (Dec. 2015) PP 26-32 www.iosrjournals.org

4. Kalter H, Warkany J. Medical progress. Congenital malformations: etiologic factors and their role in prevention(first of two parts).NEngl J Med.1983Feb 24; 308(8):424-31.DOI:10.1056/NEJM198302243080 804
5. Nelson text book of pediatrics: 19th Edition.

6. Congenital malformations : Annette Quei Ber Luft, Jurgan Spranger : DtschArztebl 2006; 103(38) : A 2464-71/ www.aerzleblatt.de

7. Grover N. Congenital malformations in Shimla. Indian J Pediatr. 2000 Apr;67(4):249-51.

8. Obu HA, ChinawaJM, Uleanya ND, et al. Congenital malformations among newborns admitted in the neonatal unit of a tertiary hospital in Enugu, South-East Nigeria--a retrospective study. BMC Res Notes. 2012 Jul 10;5:177. doi: 10.1186/1756-0500-5-177.

9. Birch MR, Grayson N, Sullivan EA. AIHW Cat. No. PER 23. Birth Anomalies Series No. 1. Sydney: AIHW National Perinatal Statistics Unit; 2004. Recommendations for development of a new Australian birth anomalies system: A review of the congenital malformations and birth defects data collection.

10. Mohanty C, Mishra OP, Das BK, Bhatia BD, Singh G. Congenital malformations in newborns: A study of 10,874 consecutive births. J Anat Soc India. 1989;38: 101-11.

11. Chaturvedi P, Banerjee KS. Spectrum of congenital malformations in the newborns from rural Maharashtra. Indian J Pediatr. 1989 Jul-Aug;56(4):501-7.

12. Khatemi F, Mamoori GA. Survey of congenital major malformations in 10/000 newborns. Iran J Pediatr. 2005;15:315-20.

13. Tomatir AG, Demirhan H, Sorkun HC, Köksal A, Ozerdem F, Cilengir N. Major congenital anomalies: A five-year retrospective regional study in Turkey. Genet Mol Res. 2009;8:19-27.

14. Mir NA, Galczek WC, Soni A. et al.Easily identifiable congenital malformations in children: Survey of incidence and pattern in 32,332 live born neonates.Ann SaudiMed. 1992Jul;12(4):366- 71.

15. Dutta V, Chaturvedi P. Congenital malformations in rural Maharashtra. Indian Pediatr. 2000 Sep;37(9):9981001 .

16. Suguna Bai NS, Mascarene M, Syamalan K, et al. An etiological study of congenital malformation in the newborn. Indian Pediatr. 1982 Dec;19(12):1003-7. 


\section{Letter to Editor}

17. Gupta RK, Singh A, Gupta R. Pattern of congenital anomalies in newborn at birth: A hospital based prospective study. Proceedings of the 42nd National Conference of Indian Academy of Pediatrics (Pedicon); Jan 6-9; Kolkata, India. 2005.

18. Swain S, Agrawal A, Bhatia BD. Congenital malformations at birth. Indian Pediatr. 1994 Oct; 31 (10): 1187-91.

19. Verma M, Chhatwal J, Singh D. Congenital malformations--a retrospective study of 10,000 cases. Indian J Pediatr. 1991 Mar-Apr;58(2):245-52.

20. Dutta V, Chaturvedi P. Congenital malformations in rural Maharashtra. Indian Pediatr. 2000 Sep; 37 (9):9981001
21. Mohanty C, Mishra OP, Das B.K, Bhatia BD, Singh G. Congenital Malformation in Newborn. A study of 10874 consecutive births. J Anat Soc. India. 1989; 38: 101-11

22. Mathur BC, Karan S, Vijaya Devi KK. Congenital malformations in the newborn. Indian Pediatr. 1975 Feb;12(2):179-83.

23. Suguna Bai NS, Mascarene M, Syamalan K, et al. An etiological study of congenital malformation in the newborn. Indian Pediatr. 1982 Dec; 19 (12): 1003-7.

\section{How to cite this article?}

Dey S, Pal A.C, Nandi MK, Agarwalla P. A study on prevalence and pattern of clinically recognisable congenital malformations in babies born in a rural medical college hospital in West Bengal, India. Int J Pediatr Res. 2018;5(11):557563.doi:10.17511/ijpr.2018.i11.02. 